\title{
Solubility of Pyrene in Binary Alcohol + Cyclohexanol and Alcohol + 1-Pentanol Solvent Mixtures at $299.2 \mathrm{~K}$
}

\author{
Mary E. R. McHale, Ann-Sofi M. Horton, Sandra A. Padilla, Ashantè L. Trufant, \\ Noé U. De La Sancha, Ernesto Vela, and William E. Acree, J r.*
}

Department of Chemistry, University of North Texas, Denton, Texas 76203-0068

\begin{abstract}
Experimental solubilities are reported for pyrene dissolved in five binary alcohol + cyclohexanol and seven binary alcohol +1 -pentanol solvent mixtures at $26^{\circ} \mathrm{C}$. Alcohol cosolvents include 1-propanol, 2-propanol, 1-butanol, 2-butanol, 2-methyl-1-propanol, 3-methyl-1-butanol, and 2-pentanol. Results of these measurements are used to test two mathematical representations based upon the combined nearly ideal binary solvent (NIBS)/Redlich-Kister equation and modified Wilson model. For the 12 systems studied, both equations were found to provide an accurate mathematical representation of the experimental data, with an overall average absolute deviation between measured and calculated values being on the order of $0.5 \%$.
\end{abstract}

\section{Introduction}

Solid-liquid equilibrium data of organic nonelectrolyte systems are becoming increasingly important in the petroleum industry, particularly in light of present trends toward heavier feedstocks and known carcinogenicity/ mutagenicity of many of the larger polycyclic aromatic compounds. Solubility data for a number of polycyclic aromatic hydrocarbons (i.e., anthracene and pyrene) and heteroatom polynudear aromatics (i.e., carbazole, dibenzothiophene, and xanthene) have been published in the recent chemical literature (for listing of references see: Acree, 1994, 1995a,b). Despite efforts by experimental ists and scientific organizations, in terms of both new experimental measurements and critically-evaluated data compilations, there still exist numerous systems for which solubility data are not readily available.

To address this problem, researchers have turned to group contribution methods and semi-empirical expressions to predict desired quantities. Group contribution methods have proved fairly successful in estimating solid solubility in pure and binary solvent mixtures from structural information. Practical application, though, is limited to systems for which all group interaction parameters are known. Interaction parameters can be evaluated from liquid-vapor, liquid-liquid, and solid-liquid equilibria data. It is important that the data base contain as many different functional groups as possible, preferably with adequate representation from both mono- and multifunctional solute/solvent molecules to permit evaluation of potential synergistic effects. The data base should contain sufficient experimental values near infinite dilution in the event that one wishes to determine separate interaction parameters for finite concentration and infinite dilution activity coefficient predictions.

Continued devel opment of solution models for describing the thermodynamic properties of a solute in binary solvent systems requires that a large data base be available for assessing the applications and limitations of derived expressions. Currently, only a limited data base exists for crystalline nonelectrolyte solubility in binary solvent mixtures. For this reason, pyrene solubilities were determined in five binary alcohol + cyclohexanol and seven binary

* To whom correspondence should be addressed. E-mail: acree@cas1. unt.edu. alcohol + 1-pentanol solvent mixtures. Results of these measurements are used to further test the descriptive abilities of several previously derived expressions.

\section{Experimental Methods}

Pyrene (Aldrich, 99\%) was recrystallized several times from anhydrous methanol, giving a purified sample that melted at $\mathrm{T}_{\mathrm{mp}} / \mathrm{K}=426.2 \pm 0.5$. Cydlohexanol (Aldrich, 99\%) was dried over molecular seives and stored at a temperature of about $30^{\circ} \mathrm{C}$, which was slightly above its melting point. 1-Propanol (Aldrich, 99+\%, anhydrous), 2-propanol (Aldrich, 99+\%, anhydrous), 1-butanol (Aldrich, HPLC, 99.8\%), 2-butanol (Aldrich 99+\%, anhydrous), 2-methyl-1-propanol (Aldrich, 99+\%, anhydrous), 1-pentanol (Aldrich, 99+\%), 2-pentanol (Acros, 99+\%), 3-methyl1-butanol (Aldrich, 99+\%, anhydrous), and 4-methyl-2pentanol (Acros, 99+\%) were stored over anhydrous sodium sulfate and molecular sieves before being fractionally distilled. Gas chromatographic analysis showed solvent purities to be $99.5 \mathrm{~mol} \%$ or better. Karl Fischer titration gave water contents (mass/mass \%) of $<0.04 \%$ for cyclohexanol and of $<0.01 \%$ for the remaining nine alcohols. Binary solvent mixtures were prepared by mass so that compositions could be calculated to 0.0001 mole fraction.

Excess solute and solvent were placed in amber glass bottles and allowed to equilibrate in a constant temperature water bath at $(26.0 \pm 0.1){ }^{\circ} \mathrm{C}$ for at least 3 days (often longer). To prevent evaporation, bottles were sealed with Parafilm, which was then wrapped several times with tape. Attainment of equilibrium was verified both by repetitive measurements after a minimum of 3 additional days and by approaching equilibrium from supersaturation by preequilibrating the solutions at a higher temperature. Aliquots of saturated pyrene solutions were transferred through a coarse filter into a tared volumetric flask to determine the amount of sample and diluted quantitatively with methanol for spectrophotometric analysis at $372 \mathrm{~nm}$ on a Bausch and Lomb Spectronic 2000. Concentrations of the dilute solutions were determined from a BeerLambert law absorbance versus concentration working curve. Molar absorptivities of the nine standard solutions varied systematically with molar concentration, and ranged from about $\epsilon / \mathrm{L} \cdot \mathrm{mol}^{-1} \cdot \mathrm{cm}^{-1}=234$ to $\epsilon / \mathrm{L} \cdot \mathrm{mol}^{-1} \cdot \mathrm{cm}^{-1}=220$ for pyrene concentrations ranging from $\mathrm{C} / \mathrm{M}=8.31 \times 10^{-4}$ to $\mathrm{C} / \mathrm{M}=4.15 \times 10^{-3}$. Identical molar absorptivities were 
J ournal of Chemical and Enginering Data, Vol. 41, No. 6, 19961523

Table 1. Experimental Mole Fraction Solubilities of Pyrene $\left(x_{A}^{\text {sat }}\right)$ in Binary Alcohol (B) + Cyclohexanol (C) Solvent Mixtures at $26.0^{\circ} \mathrm{C}$

\begin{tabular}{|c|c|c|c|}
\hline$x_{C}^{0}$ & $x_{A}^{\text {sat }}$ & $x_{C}^{0}$ & $x_{A}^{\text {sat }}$ \\
\hline $\begin{array}{l}0.0000 \\
0.0781 \\
0.1516 \\
0.3047 \\
0.4046\end{array}$ & $\begin{array}{l}\text { ropanol (B } \\
0.00426 \\
0.00472 \\
0.00515 \\
0.00596 \\
0.00645\end{array}$ & $\begin{array}{l}\text { Iohexanc } \\
0.5200 \\
0.7425 \\
0.8714 \\
1.0000\end{array}$ & $\begin{array}{l}0.00715 \\
0.00830 \\
0.00905 \\
0.00965\end{array}$ \\
\hline $\begin{array}{l}0.0000 \\
0.0701 \\
0.1412 \\
0.3172 \\
0.4155\end{array}$ & $\begin{array}{l}\text { ropanol (B } \\
0.00290 \\
0.00333 \\
0.00369 \\
0.00475 \\
0.00544\end{array}$ & $\begin{array}{l}\text { Iohexanc } \\
0.4844 \\
0.7325 \\
0.8429 \\
1.0000\end{array}$ & $\begin{array}{l}0.00592 \\
0.00774 \\
0.00846 \\
0.00965\end{array}$ \\
\hline $\begin{array}{l}0.0000 \\
0.0909 \\
0.1807 \\
0.3601 \\
0.4609\end{array}$ & $\begin{array}{l}\text { utanol (B } \\
0.00622 \\
0.00660 \\
0.00695 \\
0.00755 \\
0.00798\end{array}$ & $\begin{array}{l}\text { lohexano } \\
0.5691 \\
0.7780 \\
0.8828 \\
1.0000\end{array}$ & $\begin{array}{l}0.00831 \\
0.00903 \\
0.00928 \\
0.00965\end{array}$ \\
\hline $\begin{array}{l}0.0000 \\
0.0761 \\
0.1918 \\
0.3434 \\
0.4546\end{array}$ & $\begin{array}{l}\text { utanol (B } \\
0.00439 \\
0.00486 \\
0.00545 \\
0.00619 \\
0.00675\end{array}$ & $\begin{array}{l}\text { lohexano } \\
0.5668 \\
0.7664 \\
0.8723 \\
1.0000\end{array}$ & $\begin{array}{l}0.00738 \\
0.00853 \\
0.00906 \\
0.00965\end{array}$ \\
\hline \multicolumn{4}{|c|}{ 2-Methyl-1-propanol (B) + Cyclohexanol (C) } \\
\hline $\begin{array}{l}0.0000 \\
0.0856 \\
0.1616 \\
0.3421 \\
0.4516\end{array}$ & $\begin{array}{l}0.00326 \\
0.00370 \\
0.00403 \\
0.00497 \\
0.00557\end{array}$ & $\begin{array}{l}0.5570 \\
0.7691 \\
0.8821 \\
1.0000\end{array}$ & $\begin{array}{l}0.00631 \\
0.00775 \\
0.00861 \\
0.00965\end{array}$ \\
\hline
\end{tabular}

obtained for select pyrene standard solutions that contained up to 5 volume \% of the neat alcohol cosolvents. Experimental molar concentrations were converted to (mass/mass) solubility fractions by multiplying by the molar mass of pyrene, volume(s) of volumetric flask(s) used, and any dilutions required to place the measured absorbances on the Beer-Lambert law absorbance versus concentration working curve and then dividing by the mass of the saturated solution analyzed. Mole fraction solubilities were computed from (mass/mass) solubility fractions using the molar masses of the solute and solvent. Experimental pyrene solubilities in the 12 binary solvent mixtures studied are listed in Tables 1 and 2. Also measured was the mole fraction solubility of $x_{A}^{\text {sat }}=0.00621$ for pyrene dissolved in neat 4-methyl-2-pentanol. Numerical values represent the average of between four and eight independent determinations, with the measured values being reproducible to within $\pm 1.5 \%$.

\section{Results and Discussion}

Acree and co-workers (Acree and Zvaigzne, 1991; Acree et al., 1991; Acree 1992) suggested possible mathematical representations for isothermal solubility data based upon either a combined NIBS/Redlich-Kister model

$\ln x_{A}^{\text {sat }}=x_{B}^{o} \ln \left(x_{A}^{\text {sat }}\right)_{B}+x_{C}^{o} \ln \left(x_{A}^{\text {sat }}\right)_{C}+x_{B}^{o} x_{C}^{o} \sum_{i=0}^{N} S_{i}\left(x_{B}^{o}-x_{C}^{o}\right)^{i}$

or modified Wilson equation (Comer and Kopecni, 1990)

$$
\begin{gathered}
\ln \left[a_{A}(s) / x_{A}^{\text {sat }}\right]=1-x_{B}^{o}\left\{1-\ln \left[a_{A}(s) /\left(x_{A}^{s a t}\right)_{B}\right]\right\} /\left(x_{B}^{o}+\right. \\
\left.x_{C}^{o} \Lambda_{B C}^{\text {adj }}\right)-x_{C}^{o}\left\{1-\ln \left[a_{A}(s) /\left(x_{A}^{\text {sat }}\right)_{C}\right]\right\} /\left(x_{B}^{o} \Lambda_{C B}^{\text {adj }}+x_{C}^{o}\right)
\end{gathered}
$$

where the various $S_{i}$ and $\Lambda_{i j}^{\text {adj }}$ "curve-fit" parameters can
Table 2. Experimental Mole Fraction Solubilities of Pyrene $\left(x_{A}^{\text {sat }}\right)$ in Binary Alcohol (B) + 1-Pentanol (C) Solvent Mixtures at $26.0^{\circ} \mathrm{C}$

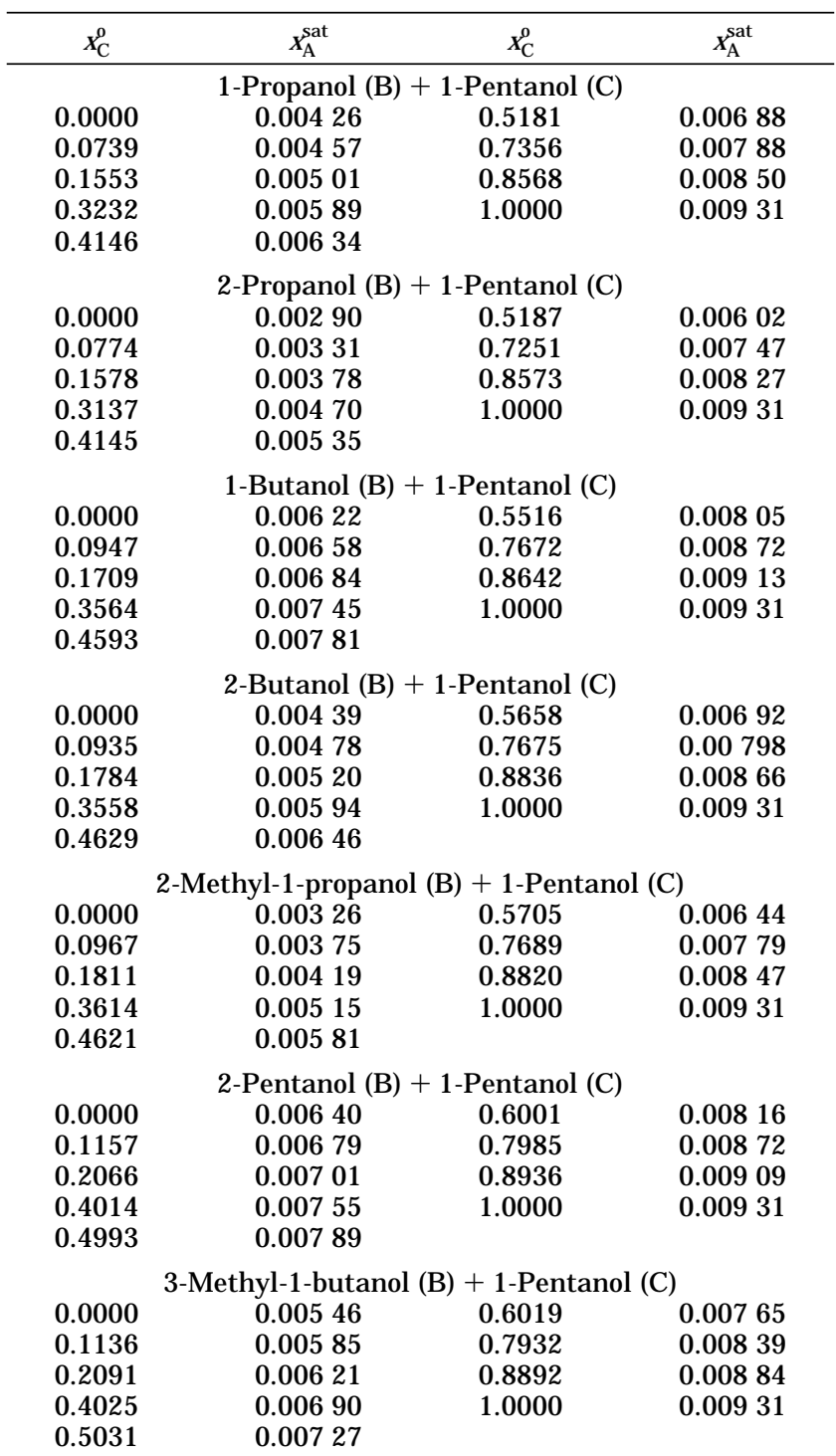

be evaluated via least squares analysis. In eqs 1 and 2 $x_{B}^{\circ}$ and $x_{C}^{0}$ refer to the initial mole fraction composition of the binary solvent calculated as if the solute were not present, $a_{A}(s)$ is the activity of the solid solute, and $\left(x_{A}^{\text {sat }}\right)_{i}$ is the saturated mole fraction solubility of the solute in pure solvent $i$. The solute activity is defined as the ratio of the fugacity of the solid to the fugacity of the hypothetical pure supercooled liquid solute. The numerical value of $a_{A}(s)=$ 0.1312 (J udy et al., 1987) used in the modified Wilson computations was calculated from

$$
\text { In } \mathrm{a}_{\mathrm{A}}(\mathrm{s})=-\Delta_{\text {fus }} \mathrm{H}_{\mathrm{A}}\left(\mathrm{T}_{\mathrm{mp}}-\mathrm{T}\right) /\left(\mathrm{RTT}_{\mathrm{mp}}\right)
$$

the molar enthalpy of fusion, $\Delta_{\text {fus }} \mathrm{H}_{\mathrm{A}} / \mathrm{J} \mathrm{mol}^{-1}=17110$ (Casellato et al., 1973), at the normal melting point temperature of the solute, $T_{\mathrm{mo}} / \mathrm{K}=424.4$.

The ability of eqs 1 and 2 to mathematically represent the experimental solubility of pyrene in the 12 binary alcohol + alcohol solvent systems is summarized in Table 3 in the form of "curve-fit" parameters and percent deviations in back-calculated solubilities. Careful examination of Table 3 reveals that both equations provide an accurate mathematical representation for how the solubility of pyrene varies with solvent composition. For the 12 pyrene systems studied, the overall average absolute deviation 
Table 3. Mathematical Representation of Pyrene Solubilities in Several Binary Alcohol (B) + Cyclohexanol (C) and Alcohol (B) + 1-Pentanol (C) Solvent Mixtures

\begin{tabular}{|c|c|c|c|c|}
\hline \multirow{2}{*}{$\begin{array}{c}\text { binary solvent system } \\
\text { component (B) }+ \\
\text { component (C) }\end{array}$} & \multicolumn{2}{|c|}{ eq 1} & \multicolumn{2}{|c|}{ eq 2} \\
\hline & $\mathrm{Si}^{\mathrm{a}}$ & $\begin{array}{c}\% \\
\operatorname{dev}^{b}\end{array}$ & $\Lambda_{\mathrm{ij}}^{\mathrm{adj}} \mathrm{c}$ & $\begin{array}{r}\% \\
\text { dev }^{b}\end{array}$ \\
\hline 1-propanol + cyclohexanol & $\begin{array}{l}0.340 \\
0.104 \\
0.153\end{array}$ & 0.5 & $\begin{array}{l}1.550 \\
0.651\end{array}$ & 0.5 \\
\hline 2-propanol + cyclohexanol & $\begin{array}{l}0.489 \\
0.139 \\
0.178\end{array}$ & 0.8 & $\begin{array}{l}1.318 \\
0.854\end{array}$ & 0.5 \\
\hline 1-butanol + cyclohexanol & $\begin{array}{l}0.176 \\
0.053\end{array}$ & 0.3 & $\begin{array}{l}1.434 \\
0.709\end{array}$ & 0.3 \\
\hline 2-butanol + cyclohexanol & $\begin{array}{l}0.284 \\
0.100 \\
0.277\end{array}$ & 0.4 & $\begin{array}{l}1.436 \\
0.712\end{array}$ & 0.7 \\
\hline 2-methyl-1-propanol + cyclohexanol & $\begin{array}{l}0.191 \\
0.128 \\
0.114\end{array}$ & 0.6 & $\begin{array}{l}1.144 \\
0.912\end{array}$ & 0.7 \\
\hline 1-propanol + 1-pentanol & $\begin{array}{r}0.309 \\
0.074 \\
-0.205\end{array}$ & 0.4 & $\begin{array}{l}1.724 \\
0.535\end{array}$ & 0.8 \\
\hline 2-propanol + 1-pentanol & $\begin{array}{l}0.510 \\
0.012\end{array}$ & 0.6 & $\begin{array}{l}1.434 \\
0.738\end{array}$ & 0.3 \\
\hline 1-butanol + 1-pentanol & $\begin{array}{r}0.148 \\
-0.042 \\
0.157\end{array}$ & 0.4 & $\begin{array}{l}1.231 \\
0.854\end{array}$ & 0.4 \\
\hline 2-butanol + 1-pentanol & 0.144 & 0.5 & $\begin{array}{l}1.347 \\
0.709\end{array}$ & 0.4 \\
\hline 2-methyl-1-propanol + 1-pentanol & $\begin{array}{l}0.359 \\
0.077\end{array}$ & 0.4 & $\begin{array}{l}1.492 \\
0.651\end{array}$ & 0.4 \\
\hline 2-pentanol + 1-pentanol & $\begin{array}{l}0.062 \\
0.000 \\
0.131\end{array}$ & 0.4 & $\begin{array}{l}1.289 \\
0.767\end{array}$ & 0.4 \\
\hline 3-methyl-1-butanol + 1-pentanol & $\begin{array}{l}0.074 \\
0.024\end{array}$ & 0.2 & $\begin{array}{l}1.231 \\
0.796\end{array}$ & 0.2 \\
\hline
\end{tabular}

a Combined NIBS/Redlich-Kister curve-fit parameters are ordered as $\mathrm{S}_{0}, \mathrm{~S}_{1}$, and $\mathrm{S}_{2} \cdot{ }^{\mathrm{b}}$ Deviation $(\%)=(100 / 7) \sum \mid\left[\left(x_{\mathrm{A}}^{\text {sat }}\right)_{i}^{\text {calc }}-\right.$ $\left.\left(x_{A}^{\text {sat }}\right)_{i}^{\exp }\right] /\left(x_{A}^{\text {sat }}\right)_{i}^{\text {exp }} \mid$. c Adjustable parameters for the modified Wilson equation are ordered as $\Lambda_{\mathrm{BC}}^{\mathrm{adj}}$ and $\Lambda_{\mathrm{CB}}^{\mathrm{adj}}$.

between experimental and calculated values is $0.4 \%$ and $0.5 \%$ for eqs 1 and 2 , respectively, which is less than the experimental uncertainty.

From a computational standpoint, eq 1 will likely be preferred because most research groups involved in reporting thermodynamic properties have computer programs for evaluating the Redlich-Kister coefficients. With this idea in mind, we recommend not only that the future presentation of experimental isothermal solubility data for slightly soluble solid solutes dissolved in binary solvent mixtures include a tabulation of the actual observed values but also, if possible, that the solubility data be mathematically represented by eq 1 . Realizing that a single equation will not be applicable to all systems encountered, we further suggest eq 2 as an alternative mathematical representation for systems having extremely large solubility ranges and/ or highly asymmetrical In $x_{A}^{\text {sat }}$ versus $x_{B}^{0}$ curves, such as the carbazole + alkane + tetrahydropyran systems reported previously (Acree et al., 1991).

\section{Literature Cited}

Acree, W. E., J r. Mathematical Representation of Thermodynamic Properties. Part 2. Derivation of the Combined Nearly I deal Binary Solvent (NIBS)/Redlich-Kister Mathematical Representation from a Two-Body and Three-Body Interactional Mixing Model. Thermochim. Acta 1992, 198, 71-79.

Acree, W. E., J r. Polycydlic Aromatic Hydrocarbons in Pureand Binary Solvents; Vol. 54 in IUPAC Solubility Data Series; Oxford University Press: Oxford, United Kingdom, 1994.

Acree, W. E., J r. Polycyclic Aromatic Hydrocarbons: Binary Nonaque ous Systems: Part 1 (Solutes A-E); Vol. 58 in IUPAC Solubility Data Series; Oxford University Press: Oxford, United Kingdom, 1995a.

Acree, W. E., J r. Polycyclic Aromatic Hydrocarbons: Binary Nonaque ous Systems: Part 2 (Solutes F-Z); Vol. 59 in IUPAC Solubility Data Series; Oxford University Press: Oxford, United Kingdom, 1995b.

Acree, W. E., J r.; Zvaigzne, A. I. Thermodynamic Properties of Nonelectrolyte Solutions. Part 4. Estimation and Mathematical Representation of Solute Activity Coefficients and Solubilities in Binary Solvents Using the NIBS and Modified Wilson Equations. Thermochim. Acta 1991, 178, 151-167.

Acree, W. E.., J r.; McCargar, J. W.; Zvaigzne, A. I.; Teng, I.-L. Mathematical Representation of Thermodynamic Properties. Carbazole Solubilities in Binary Alkane + Dibutyl Ether and Alkane + Tetrahydropyran Solvent Mixtures. Phys. Chem. Liq. 1991, 23, 27-35.

Casellato, F.; Vecchi, C.; Girelli, A.; Casu, B. Differential Calorimetric Study of Polycydic Aromatic Hydrocarbons. Thermochim. Acta 1973, 6, 361-368.

Comer, J . F.; Kopecni, M. M. Prediction of Gas Chromatography Solute Activity Coefficients in Mixed Stationary Phases Based on the Wilson Equation. Anal. Chem. 1990, 62, 991-994.

J udy, C. L.; Pontikos, N. M.; Acree, W. E., J r. Solubility of Pyrene in Binary Solvent Mixtures Containing Cyclohexane. J. Chem. Eng. Data 1987, 32, 60-62.

Received for review J une 26, 1996. Accepted September 3, 1996. ${ }^{\otimes}$ S.A.P., A.L.T., N.U.D.L.S. and E.V. thank the U.S. Department of Education for support provided to them under the Upward Bound Math and Science Program.

\section{J E 9602172}

${ }^{\otimes}$ Abstract published in Advance ACS Abstracts, October 15, 1996. 